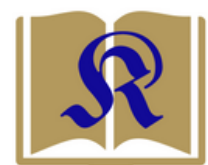

KURIOS
KURIOS

(Jurnal Teologi dan Pendidikan Agama Kristen)

ISSN 2615-739X (print), 2614-3135 (online)

Vol. 4, No. 1, April 2018 (39-55)

http://www.sttpb.ac.id/e-journal/index.php/kurios

\title{
Yesus Kristus Juru Ruwat Manusia: Sebuah Pendekatan Semiotika dalam Gereja Kristen Jawa
}

\author{
Kristriyanto \\ Fakultas Teologi Universitas Kristen Surakarta \\ kristiyanto@gmail.com
}

\begin{abstract}
Ruwatan is a form of ceremony in Javanese society that aims to free man from bad luck or the calamity that would befall him. The term "ruwatan" also appears in the discourse of church life amid the Javanese Christian Church (GKJ) as it is written in the Javanese Bible, the Christian Song of Song (the official book song of worship) and the liturgy. This article aimed to find the understanding of the citizens of the Javanese church about ruwatan and develop it in the concept of thinking and devoting of the people church about Jesus Christ is the Man of Ruwat. The method used is a descriptive sociology of religion and culture. In conclusion, the church is expected to acknowledge, accept and respect the existence of Javanese ruwatan, to keep the existence of ruwatan as part and identity of Javanese society activity including church service.
\end{abstract}

\begin{abstract}
Abstrak
Ruwatan merupakan suatu bentuk upacara di masyarakat Jawa yang bertujuan untuk membebaskan manusia dari nasib buruk maupun malapetaka yang akan menimpa dirinya. Istilah "ruwatan" juga muncul dalam wacana kehidupan bergereja di kalangan Gereja Kristen Jawa (GKJ) sebagaimana tersurat pada Alkitab berbahasa Jawa, Kidung Pasamuwan Kristen (buku nyanyian resmi ibadah) dan liturgi. Artikel ini bertujuan untuk menemukan pemahaman warga gereja tentang ruwatan serta mengembangkannya dalam konsep berpikir dan beriman warga gereja tentang Yesus Kristus adalah Juru Ruwat manusia. Metode yang digunakan adalah deskriptif sosiologi religi dan budaya. Kesimpulannya, gereja bersikap mau mengakui, menerima dan menghormati keberadaan ruwatan Jawa, ikut menjaga keberadaan ruwatan sebagai bagian dari aktivitas dan identitas masyarakat Jawa termasuk dalam pelayanan gereja.
\end{abstract}

Article History

Submit:

14 Februari 2018

Accept:

10 April 2018

Publish:

11 April 2018

\section{Keywords:} ruwatan; Jesus Christ; man of ruwat; Javanese Christian Church; Javanese society

\section{Kata kunci:}

Gereja Kristen Jawa; Juru ruwat manusia; masyarakat Jawa; ruwatan; Yesus Kristus 


\section{Pendahuluan}

Upacara ruwatan merupakan salah satu jenis upacara yang ada dan berjalan di tengah masyarakat Jawa. Meskipun frekuensi pelaksanaannya relatif jarang, upacara ini masih tetap berlangsung dan menjadi bagian dari kehidupan masyarakat, dengan pemahaman bahwa upacara ruwatan merupakan realitas yang masih berlangsung di tengah masyarakat Jawa. ${ }^{1}$ Apakah ini berarti bahwa warga gereja, khususnya Gereja Kristen Jawa (GKJ), yang hidup di tengah masyarakat akan terpengaruh dan ikut serta dalam pelaksanaan tersebut? Kebanyakan warga gereja menjawab bahwa mereka tidak terlibat (secara aktif maupun pasif) dalam upacara ini. Mereka berpandangan bahwa upacara ruwatan tidaklah berguna bagi dirinya, setelah mereka percaya dan menjadi milik Yesus Kristus dan hidup sebagai orang Kristen.

Warga gereja menyampaikan pandangan dan keyakinannya, bahwa realitas baptis Kristen yang telah mereka terima merupakan suatu bentuk ruwatan, yang mereka namakan sebagai ruwatan Kristen. Secara sederhana mereka memaknai bahwa orang-orang Kristen sudah menerima ruwatan, yang dilakukan oleh Yesus Kristus sendiri melalui peristiwa baptis. Istilah ruwatan dimengerti sebagai kesamaan istilah dengan penyelamatan, pembersihan, pencucian, penebusan, penghilangan yang dikaitkan dengan dosa-dosa manusia. Hal itu berarti, sebagai pengikut Kristus, orang Kristen sudah dibersihkan, diselamatkan, ditebus, dihilangkan dosa-dosanya, sehingga mendapatkan keselamatan oleh karya Yesus Kristus tersebut. Hidupnya bukan lagi di dalam kungkungan dosa, tetapi dalam persekutuan dan keselamatan Yesus Kristus.

Mengapa warga gereja memiliki pandangan seperti itu? Jawaban atas pertanyaan ini lebih cenderung pada kesederhanaan warga gereja dalam berpikir. Sebagai orang Jawa yang telah mengetahui dan memahami arti ruwatan, warga gereja mengenakan pemahaman dan pengetahuan tersebut ke dalam lingkup komunitas gereja. Warga gereja dapat memahami makna yang terkandung di dalam pelaksanaan upacara ruwatan tersebut, yakni membersihkan 'kotoran' yang melingkupi hidup manusia, sehingga orang-orang penerima ruwatan dapat hidup secara sejahtera dan bahagia, tanpa ada pengganggu di 'jalan hidup' yang akan mereka tempuh waktu berikutnya. Hal ini berarti, meski ruwatan merupakan tradisi masyarakat Jawa, yang secara langsung tidak menjadi tradisi Kristen (khususnya Gereja Kristen Jawa), namun ide dan makna ruwatan berada dalam benak warga gereja dan tetap menempel dalam proses berpikir mereka dalam hidup bergereja.

\footnotetext{
${ }^{1}$ Sunarno, "Indigenous : Jurnal Ilmiah Berkala Psikologi.," Indigenous: Jurnal Ilmiah Psikologi 11, no. 2 (November 1, 2009), accessed March 26, 2018, http://journals.ums.ac.id/index.php/indigenous/article/view/1619/1152.
} 
Kedekatan warga gereja dengan istilah dan pemahaman ruwatan sudah masuk pada interaksi dan penjiwaan dalam kehidupan sehari-hari, termasuk hidup religiositas warga gereja. Hal ini dapat diketahui dari penggunaan istilah tersebut dalam Kitab Suci (Alkitab berbahasa Jawa), seperti di bawah ini:

"Wondene Paduka, dhuh Sang Yehuwah, Paduka nguningani, sadaya rancanganipun anggenipun badhe mejahi kawula. Sampun Paduka apunten kalepatanipun, lan sampun Paduka ruwat dosanipun saking ngarsa Paduka : Nanging mugi sami kesandhungga wonten ing ngarsa Paduka. Mugi karsaa tumindak ing dinten bebendu Paduka! (Yeremia $18: 23)$.

"Prabu Dawud banjur ngandika marang Nabi Natan: "Kula sampun nglampahi dosa wonten ing ngarsanipun Sang Yehuwah, "Lan Nabi Natan matur marang Prabu Dawud: "Sang Yehuwah sampun ngruwat dosa dalem, panjenengan dalam boten badhe seda." (II Samuel $12: 13$ ).

"Lan Panjenengane iku kang dadi pangruwate dosa kita, lan ora ngemungake dosa kita bae, nanging malah iya dosane wong sajagad kabeh." (I Yokanan 2 : 2).

"Katresnan iku mangkene : Dudu kita kang wus padha tresna marang Gusti Allah, nanging Gusti Allah kang wus nresnani kita lan wus ngutus Kang Putra minangka pangruwating dosa kita" (I Yokanan 4 : 10).

Dalam lagu-lagu ibadah, kata-kata yang berasal dari kata dasar ruwat juga banyak digunakan. Dalam Kidung Pasamuan Kristen terbitan Badan Musyawarah Gereja-Gereja berbahasa Jawa menunjukkan hal tersebut.

Sang Kristus Gusti Maha Mulya, tedhak mring bumi lan manjalma Ngesorken srira pindha abdi, ngruwat tyang dosa mrih basuki.

Pra tyang pracaya bra wratakna Injil kang suci salaminya.

Tan ajrih geter was ing driya, wit Gusti nganthi salaminya.

(KPK 260 bait 1 )

Sinalib ing Golgota Putraning Allah seda

Wit dadya kurban sanyata, nggih ngruwat manungsa dosa

Naraka wah antaka kwasane den sirnakna

Saliring tyang winengan korining Kraton swarga

Ing Golgota Gusti seda marginira

Gung manungsa mardika gesang nyata.

(KPK 257 bait 1 )

Aku duwe Pamarta, Yesus Kristus asmanya

Kang wus ngurbanken sarira, ngruwat aku sing dosa

Duwekku, duwekku, Gusti Yesus Pamartaku

Dak puji trus ing kalbu.

(KPK 13 bait 1) 
Tujuan penelitian ini adalah: (1) menemukan pemahaman warga gereja tentang ruwatan yang terjadi di tengah masyarakat Jawa; (2) mengembangkan pengertian dan makna yang benar tentang ruwatan, yang telah dimanfaatkan warga gereja dalam menjelaskan penyelamatan Allah kepada manusia; (3) mengembangkan konsep berpikir dan beriman warga gereja tentang Yesus Kristus adalah Juru Ruwat manusia dan; (4) menemukan makna teologis "Yesus Kristus Juru Ruwat manusia" dalam kerangka pembangunan jemaat.

\section{Ruwatan}

Ruwatan, dalam konteks budaya Jawa, adalah tumindak kangge ngicali sukerta utawi sesuker, amrih manungsa saged kalis saking memangsanipun Kala (tindakan untuk menghilangkan gangguan atau kotoran, agar manusia bebas dari sasaran mangsa batara Kala). ${ }^{2}$ Sukerta atau sesuker akan menjadikan manungsa nampeni karibedan ing gesangipun lan tebih saking katentreman lan kawilujengan (manusia memperoleh gangguan dalam hidupnya dan jauh dari kesejahteraan dan keselamatan). Dari sisi inisiatif, ruwatan minangka tumindaking manungsa kangge pados kawilujengan (ruwatan sebagai tindakan manusia di dalam mencari keselamatan). Tumindaking manungsa kangge ngupadi sageda uwal saking blengguning swasana ajrih, sumelang, mboten nyamar. Mila, mboten kajiret malih utawi kalis sing karibedan (tindakan manusia, dalam berupaya aktif kiranya dapat terlepas dari belenggu ketakutan dan was-was). Kodrat dipunwiradati utawi kanthi dipun sranani. (meski manusia telah ditentukan keberadaannya oleh kodrat atau kuasa Tuhan, tetapi manusia dapat berupaya mencari perantara, agar bias terlepas dari hal yang menyengsarakan dalam kodrat tersebut). Arah atau kepentingan ruwatan adalah keselamatan serta terbebas dari belenggu ketakutan dan was-was. ${ }^{3}$

Keselamatan merupakan kalis saking memangsanipun Kala (bebas dari sasaran mangsa Kala), artinya tidak ada permasalahan hidup yang menghadang perjalanan hidupnya., supados gesangipun mboten punggel ing satengahing margi (agar hidupnya tidak terputus di tengah jalan alias agar berumur panjang). Supados panyuwunanipun saged ginayuh (agar permohonannya dapat terkabul). Tebih saking bebaya menapadene raos samar lan wah sumelang (jauh dari mara bahaya serta rasa kuatir dan was-was). Ruwatan inggih punika lampahing manungsa anggenipun pados usada saking panguwaosing zat-zat ghaib (aura)

\footnotetext{
${ }^{2}$ Sugeng Rahanto, "PENGARUH RUWATAN MURWOKOLO TERHADAP KESEHATAN," Buletin Penelitian Sistem Kesehatan. 15, no. 3 (2012): 282-288, accessed March 26, 2018, http://ejournal.litbang.depkes.go.id/index.php/hsr/article/view/3002/2236.

${ }^{3}$ Ibid.
} 
reged ingkang nglimputi manungsa. Ruwatan merupakan tindakan manusia di dalam mencari obat dari kekuasaan zat-zat gaib atau aura kotor yang menguasai manusia.

Berkenaan dengan keselamatan, ruwatan minangka srana anggenipun manungsa sageda menggak nepsuning kadonyan ing sadinden-dinten, awit manungsa gesang tumuju kamulyan kedah wonten srananipun (ruwatan merupakan sarana/jalan di dalam manusia berupaya menahan nafsu duniawi sehari-hari, oleh karena manusia hidup menuju kesejahteraan harus melalui suatu sarana/jalan). Memperhatikan faktor keseimbangan, ruwatan merupakan usaha menetralisir kekuatan atau pengaruh jahat Kala dalam diri manusia dengan kekuatan baik dari Allah melalui Wisnu, yang dilakukan oleh dalang. ${ }^{4}$

Ada pendapat yang menyatakan ruwatan adalah "jalan pintas" manusia di dalam berupaya memperoleh keselamatan dan luwar saking karibedan (terlepas dari gangguan permasalahan). Ada juga pendapat yang menyatakan ruwatan merupakan tindakan simbolis manusia memberi tumbal (tolak bala) kepada Kala, sehingga Kala tidak lagi mengganggu manusia. ${ }^{5}$ Ada pula pendapat yang menyatakan ruwatan bermaksud namengi manungsa saking panggodha, wah kuwatos, ingkang tansah nempuh pagesanganing manungsa (memberi perisai bagi manusia dari godaan dan kekuatiran, yang senantiasa mengancam kehidupan manusia).

\section{Ruwatan bagi Orang Kristen}

"Gusti Yesus sampun rawuh ing jagad, ngruwat dosaning manungsa. Mila manungsa sampun resik saking sakathahing dosa saha nampeni kawilujengan." (Tuhan Yesus telah datang ke dunia,menebus dosa manusia. Sehingga manusia telah bersih dari segala dosa dan menerima keselamatan). Jika mereka menjalani ruwatan, itu berarti mereka bersikap tidak menghormati alias merendahkan keselamatan yang sudah diberikan Tuhan Yesus kepadanya. Hal ini berarti juga tidak menghormati labuh-labetipun Gusti Yesus ngantos seda ing kajeng salib, kangge milujengaken manungsa dosa (jasa melalui kesengsaraan dan penderitaan yang dilakukan oleh Yesus Kristus sampai Ia wafat untuk menyelamatkan manusia berdosa).

Mereka yang mengikuti ruwatan adalah pertanda orang-orang yang imannya (masih) lemah, mereka masih dilingkupi kekuatiran dalam hidupnya. "Tiyang ingkang ndherek ruwatan rumaosipun nguri-uri kabudayan Jawi ingkang adiluhung, ananging sayektosipun malah ngurbanaken kapitadosanipun." (orang-orang penerima ruwatan, menurut perasaannya

\footnotetext{
${ }^{4}$ Sunarno, "Indigenous : Jurnal Ilmiah Berkala Psikologi."

${ }^{5}$ Ninik Harini, "MAKNA SIMBOLIS SRIMPI LIMA PADA UPACARA RUWATAN DI DESA NGADIRESO PONCOKUSUMO MALANG," Bahasa dan Seni : Jurnal Bahasa, Sastra, Seni, dan Pengajarannya 40, no. 1 (2012), accessed March 21, 2018, http://journal2.um.ac.id/index.php/jbs/article/view/122/95.
} 
melestarikan kebudayaan Jawa yang luhur, tetapi yang terjadi sesungguhnya justru mengorbankan imannya). "Gusti Yesus sampun ngruwat manungsa sukerta, inggih kula lan panjenengan." (Tuhan Yesus telah membersihkan manusia kotor/berdosa yakni saya dan saudara). Yesus Kristus sebagai Juru Ruwat dunia yang telah melakukan ruwatan (penebusan) kepada semua manusia di dunia tanpa terbatasi waktu. Ada pendapat bahwa ruwatan termasuk tindakan nggege mangsa (bermaksud mempercepat waktu) datangnya berkat Tuhan tersebut.

Ruwatan diserahkan kepada Tuhan Yang Maha Esa dan orang-orang Kristen menyerahkan semuanya itu kepada Yesus Kristus, yang adalah Tuhannya. Orang Kristen sekaligus bagian dari masyarakat Jawa yang ngleluri (melestarikan) budayanya. Piyambakipun nindakaken minangka trah kejawen (Mereka melakukan sebagai keturunan keluarga Jawa). Upacara ruwatan merupakan symbol di dalam manusia berupaya mencari dan mendapatkan keselamatan. Orang Kristen yang mengikuti upacara ruwatan, maka keikutsertaan mereka dapat disebut ikut menjaga ruwatan sebagai wasita adi (nasihat luhur).

Boleh atau tidaknya warga gereja mengikuti upacara ruwatan Jawa, lebih baik diputuskan dalam sidang Majelis terlebih dahulu. Bila mereka mengikuti hanya karena faktor ikut-ikutan atau sekedar gengsi dan prestise, maka mereka diarahkan untuk tidak perlu mengikuti ruwatan.

\section{Pembahasan}

\section{Semiotik Upacara Ruwatan Jawa}

Semiotik atau semiotika merupakan padanan dari kata Yunani semeion ( $\sigma \in \mu \in \mathrm{L} O \nu)$ yang berarti "tanda". Semiotika disebut sebagai ilmu yang mempelajari berbagai obyek, peristiwa maupun kebudayaan yang kesemuanya "diposisikan" sebagai tanda-tanda. ${ }^{6}$ Semantik semiotik merupakan bentuk interpretasi atas sesuatu hal, termasuk di dalamnya adalah teks tertulis, seperti teks ruwatan.

\section{Batara Kala sebagai Simbol Kejahatan}

Batara Kala meminta ijin kepada Batara Guru kiranya diperkenankan memakan manusia sebgai pengganti batu padas makanannya. Batara Kala mengejar-ngejar Jatusmati kemana pun dia lari dan bersembunyi, dengan maksud menangkap dan memakannya. Batara Kala memberi kutukan kepada orang-orang yang menurutnya mengganggu langkah ketika akan menangkap Jatusmati. Batara Kala menangkap bayi baru lahir yang sedang dimandikan

${ }^{6}$ Diana Anugrah, “ANALISIS SEMIOTIKA TERHADAP PROSESI PERNIKAHAN ADAT JAWA "TEMU MANTEN" DI SAMARINDA” 4, no. 1 (2016): 319-330, accessed March 21, 2018, http://ejournal.ilkom.fisip-unmul.ac.id/site/wp-content/uploads/2016/04/JURNAL GANJIL diana (04-23-16-0446-50).pdf. 
dan Jatusmati. Hal demikian akan menjadikan "dunia" kehidupan manusia menjadi misteri yang menakutkan, jauh dari kesejahteraan dan keharmonisan. Batara Kala adalah sumber ancaman, kutuk maupun terror yang jauh dari kerukunan, kedamaian dan kesejahteraan maupun kematian. "Peran" Batara Kala dapatlah disebutkan sebagai simbol malapetaka, kehancuran, kejahatan maupun simbol kematian. Makna istilah "batara kala" sesuai dengan peran dan perilaku yang ditunjukkan Batara Kala yakni kejahatan, malapetaka.

\section{Ki Dalang Kandabuwana sebagai Simbol Penyelamat Kehidupan}

Ki Dalang Kandabuwana adalah Batara Wisnu yang datang ke dunia menjelma atau alih rupa menjadi manusia yang berprofesi sebagai dalang bersama dengan Kalunglungan (Batara Narada) sebagai penggendang dan Saruni (Batara Brama) sebagai penggender. Ki Dalang Kandabuwana melindungi Jatusmati dan seorang bayi dari ancaman santapan Batara Kala. Ki Dalang Kandabuwana mengeluarkan "daya” yang menjadikan berhentinya gangguan keamanan maupuan kerugian material (kasus penyerangan binatang hutan ke desa Mendangtamtu). Ki Dalang Kandabuwana menghambat bahkan dapat "mengalahkan” Batara Kala melalui cara menceritakan bagaimana asal-usul Batara Kala sejak masih berujud air serta membaca titipan yang ada di tubuh Batara Kala sampai tamat. Dengan "kekalahannya", menjadikan Batara Kala mau berjanji akan menjaga keturunan Ki Dalang Kandabuwana.

“Keturunan” Ki Dalang Kandabuwana ialah mereka yang berada dalam jangkauan perlindungan Ki Dalang Kandabuwana. Melalui “daya” yang dikeluarkan oleh Ki Dalang Kandabuwana juga, terjadi kerukunan antara Rara Primpen dan Jaka Sondang, yang sebelumnya "bentrok" saling menjelek-jelekkan. Ki Dalang Kandabuwana menyetujui usul yang diajukan oleh Kyai Sapujagad berkenaan dengan penemuannya, yakni Kala Lumut dan Kala Lumer. Seperti yang dikehendaki oleh Batara Guru di dalam Ki Dalang Kandabuwana "turun" ke dunia adalah melindungi manusia agar manusia di dunia tidak punah karena dimangsa oleh Batara Kala. Simbol kehidupan dalam diri Ki Dalang Kandabuwana ditunjukkan pada kuantitas hidup (berumur panjang) juga secara kualitas (damai, harmonis, serta dekat komunikasinya dengan Yang Maha Kuasa).

\section{Jatusmati adalah Simbol Manusia Sukerta dan Terkena Malapetaka}

Orang sukerta terbagi ke dalam 3 kategori yakni (1) Anak atau orang yang "cacat kodrati" atau "cacat lahir" misalnya ontang anting (anak lelaki tunggal, seperti Jatusmati) (2) Orang "cacat" karena kelalaiannya, misalnya wong ora ngrampungake anggone mayoni omah (orang yang tidak menyelesaikan pengatapan rumah) (3) Orang yang tertimpa suatu halangan, misalnya wong kang ngrubuhake dandang (orang yang merobohkan dandang). Jatusmati 
merupakan simbol dari orang sukerta yang "terlunta-lunta" dikejar dan akan dimangsa oleh Batara Kala. Kecuali Jatusmati, terdapat 2 orang lain yang hendak dimangsa Batara Kala, yakni Batara Guru dan seorang bayi yang baru lahir. Batara Guru bisa menghadapi Batara Kala sendiri, bahkan mampu "mengalahkannya" dan menasihatinya. Sedangkan sang bayi segera mendapat pertolongan dari Ki Dalang Kandabuwana dengan cara menukarnya dengan pedang Batara Kala yang berada di tangan Ki Dalang.

\section{Perbuatan Batara Guru sebagai Simbol Munculnya si Jahat dan Malapetaka}

Kemunculan Batara Kala yakni dari kama (sperma) Batara Guru yang salah jatuh. Kama tersebut tidak membuahi Dewi Uma, sang permaisuri, tetapi jatuh di samudera, oleh karena mereka berdua sedang "terbang" menaiki Lembu Andini untuk melihat keindahan alam. Dari tetesan kama di samudera inilah kemudian muncul makhluk raksasa, berbadan kuat serta liar, dialah Batara Kala. Batara Guru memberikan ijin kepada Batara Kala untuk memakan manusia di marcapada (dunia), sebagai pengganti batu padas, jenis makanan yang dimakan sebelumnya. Dari tindakan Batara Guru inilah, Batara Kala memperoleh "hak" untuk memangsa manusia. Keputusan Batara Guru melahirkan atau memunculkan kejahatan dan malapetaka yang mengganggu dan mengancam kehidupan manusia. Melalui peran Ki Dalang Kandabuwana sebagai penjelmaan Batara Wisnu, Batara Kala dapat dihalangi langkah perburuan memangsa manusia, sekaligus "menjinakkannya". Batara Kala dimandikan atau diruwat, sehingga tidak memberi kutukan serta tidak berupaya memangsa manusia lagi.

\section{Mantera sebagai Simbol Kekuatan Gaib Ki Dalang Kandabuwana}

Mantera merupakan ungkapan yang disampaikan oleh Ki Dalang Kandabuwana yang dapat mendatangkan daya gaib, yang disadari oleh Ki Dalang kandabuwana sendiri. Ketika Ki Dalang akan menyampaikan mantera banyak dalang, maka para gadis dan ibu hamil muda dimohon untuk menyingkir (menjauh), agar tidak terkena daya gaib mantera tersebut. Ki Dalang Kandabuwana juga menerka titipan Batara Guru yang ada di tubuh Batara Kala, di mana terkaan tersebut memiliki kesejajaran dengan mantera. Oleh karena mantera yang disampaikan mampu meredakan "keganasan" Batara Kala, maka mantera Ki Dalang kandabuwana memiliki kekuatan ayng lebih tinggi dibandingkan dengan kekuatan yang dimiliki oleh Batara Kala sendiri. Kekuatan Ki Dalang kandabuwana berasal dari mantera, yang berkekuatan bersih, putih dan untuk kedamaian. 


\section{Sajian atau Sajen sebagai Simbol Kelengkapan Ruwatan}

Hampir semua oarng yang terlibat den gan pembersihan atau ruwatan ada kaitannya dengan sesuatu benda, makanan maupun uang ayng dipakai sebagai "syarat". Istilah "syarat" tampaknya bisa mewakili terhadap keberadaan benda, makanan maupun uang yang disediakan oleh mereka yang terlibat tersebut. Perlengkapan sajen atau "syarat" yang dikehendaki benar-benar pelengkap dalam peristiwa ruwatan, yang memiliki posisi yang sama pentingnya dengan mantera yang disampaikan. Antara mantera dengan "syarat" merupakan dua hal yang saling mengisi, keduanya saling membutuhkan. Mantera mengisi unsure rohaniah atau batiniah, ayng tidak terlihat, sedangkan "syarat" atau perlengkapan sesaji seluruhnya mengisi pada unsure jasmaniah, yang tampak mata. Sesaji merupakan simbol kelengkapan ruwatan, yang mesti dipenuhi dalam penyelenggaraan ruwatan.

\section{Pragmatik Semiotik dari Sisi Pencipta Teks Ruwatan}

\section{Cerita Menampilkan Suatu Usaha Mencari Kesejahteraan Hidup}

Pada akhir cerita Batara Kala, Jatusmati, Rara Primpen dan Buyut Geduwel suaminya menerima permandian dari Ki Dalang Kandabuwana. Permandian tersebut merupakan sarana yang digunakan oleh Ki Dalang Kandabuwana di dalam Batara Kala dan orang-orang tersebut menerima pembersihan diri. Batara Kala menerima pembersihan diri, sehingga tidak meneruskan "perburuannya" memangsa manusia, namun pergi dan bertempat tinggal di Kendawahana. Bahkan "sifat baik" Batara Kala ditunjukkan di hadapan Ki Dalang Kandabuwana, bahwa ia berjanji akan menjaga semua keturunan Ki Dalang. Rara Primpen "benar-benar mau" untuk kembali hidup dalam kerukunan dan kedamaian bersama suami dalam keluarga. Ki Dalang Kandabuwana sendiri memberi pagar benang putih berkeliling 3 kali serta syarat-syarat lain di rumah penanggap wayang yaitu Ki Buyut. Secara jasmaniah keduanya memperoleh kondisi tubah sehat walafiat, demikian juga secara batiniah mereka memperoleh kebahagiaan, kerukunan dan kedamaian dalam hidupnya.

Ketentuan yang diberikan kepada Batara Kala tentang manusia yang menjadi sasaran makanannya adalah: Anak dan orang sukerta; bayi yang lahir bersamaan dengan pertunjukan wayang, tetapi tidak diserahkan kepada Ki Dalang oleh orang tuanya; orang-orang yang menghalangi perjalanan Batara Kala. Batara Kala tidak mau melanggar ketentuan yang telah diberikan kepadanya maupun tidak ceroboh memangsa manusia yang dia jumpai. Meskipun menjumpai banyak orang, namun hanya orang sukerta sajalah yang dimangsa. Tindakan Batara Kala merupakan bentuk kesetiaannya pada ketentuan yang ditetapkan kepadanya. 


\section{Cerita Menampilkan Penghentian Malapetaka}

Malapetaka ialah segala kondisi yang ada sangkut pautnya dengan pertikaian, bencana, kerugian atau hal-hal yang tidak menyenangkan. Penghentian malapetaka paling tidak bersifat sementara, yakni ketika pertunjukan wayang berlangsung. Melalui pertunjukan wayang tersebut tampak adanya kedamaian, kesejahteraan, kerukunan serta jauh dari malapetaka yang menimpa desa di mana pertunjukan wayang diadakan. Ki Dalang akan dihormati oleh Pentung Luyung dan Jugil Awawawar beserta keturunannya, sehingga tidak akan diganggu oleh mereka, paling tidak dalam hal keamanan harta benda. Juga keturunan Ki Dalang akan dijaga keselamatannya oleh Batara Kala, itu berarti mereka tidak akan diganggu atau mengalami malapetaka yang berasal dari Batara Kala.

\section{Cerita Ikut Serta Menghargai Kehidupan Binatang}

Melalui dewa kerbau, dewa ayam dan dewa babi hutan, binatang datang kepada Ki Dalang Kandabuwana, agar binatang memperoleh kepedulian dari pihak manusia. Permohonan ketiga dewa tersebut adalah: (1) Manusia kiranya ikut peduli terhadap binatang yang masih hidup, agar dipelihara dengan baik-baik serta dijaga kesehatannya; (2) Memperkenankan binatang disembelih manusia, ketika hal itu untuk keperluan yang jelas dan bertanggungjawab, misal hajatan (dimengerti untuk lauk dalam sajian makan); (3) Menjaga "citra" binatang, jangan sampai binatang menjadi pengganggu manusia. Ide yang dapat disimpulkan adalah menghargai martabat binatang sebagai sesama makhluk di dunia ini, yang memiliki nyawa seperti manusia hidup bernyawa. Ruwatan memiliki tujuan untuk kesejahteraan dan kelestarian hidup manusia, hal ini sesungguhnya juga berlaku bagi binatang. Binatang sebagai makhluk ciptaan Tuhan, yang bernyawa, yang hidup di dunia, kiranya memperoleh kesejahteraan dan kelestarian hidupnya.

\section{Pragmatik Semiotik dari Sisi Pembaca Teks Ruwatan}

\section{Ki Dalang Kandabuwana Dipakai Sebagai Alat Penyelamat}

Kehadiran Ki Dalang Kandhabuwana di dunia merupakan kehendak Batara Guru untuk melindungi manusia dari jangkauan mangsa Batara Kala. Tugas ini merupakan kelanjutan dari keputusan Batara Guru yang memperkenankan Batara Kala memangsa manusia. Ki Dalang Kandhabuwana berhasil menyelamatkan Jatusmati dan bayi yang baru lahir. Selain itu ada "pertobatan" yang dilakukan oleh Batara Kala beserta dengan para prajuritnya, pencuri Pentung Luyung dan Jugil Awarawar. Dari sisi penyelamatan, keputusan "bertobat" yang mereka ambil merupakan bukti dari keberhasilan tugas ayng diemban oleh Ki 
Dalang Kandhabuwana. Ki Dalang Kandhabuwana adalah "alat" ayng dipakai dalam menciptakan keselamatan dalam diri manusia.

\section{Kekuatan Kebaikan Dapat Mengatasi Kekuatan Kejahatan}

Batara Kala merupakan simbol dari kekuatan kejahatan, sedangkan Ki Dalang Kandabuwana sendiri adalah simbol dari kekuatan kebaikan. Kemenangan Ki Dalang Kandabuwana terhadap Batara Kala ditandai dengan dia mampu menebak titipan yang ada di empat bagian tubuh Batara Kala (langit-langit, tekak, dada dan punggung), memberikan mantera, jantur (cerita), santi (doa atau pujian), matekaji (menyampaikan doa), sehingga kekuatan Batara Kala lemah. Pada akhirnya Ki Dalang Kandabuwana memandikan (meruwat) Batara Kala. Memperhatikan simbol-simbol antara keduanya, maka dapat disebutkan, bahwa kekuatan kebaikan dapat mengatasi kekuatan kejahatan. Kemenangan kekuatan kebaikan atas kekuatan kejahatan, bukanlah melalui pertarungan atau adu kekuatan fisik, tetapi melalui kekuatan batin yang bersih dari Ki Dalang Kandabuwana.

\section{Ada Jalan Menuju Kesejahteraan}

Jatusmati berkehendak terlepas dari kesengsaraan hidupnya untuk mencapai kesejahteraan. Meski jalannya sangat sulit, sampai hampir mati dimangsa Batara Kala, pada akhirnya Jatusmati memperoleh ruwatan dari Ki Dalang Kandabuwana. Buyut Geduwel dan Rara Primpen berupaya mencari kerukunan dan kesejahteraan dalam hidup bersuami-isteri. Pada akhirnya mereka mau mengakui kekurangan masing-masing dan hidup rukun. Apa yang menjadi keinginan manusia, bila telah menjadi tekadnya, dan dilakukan dengan sungguhsungguh, maka dia akan mendapatkan jalan untuk menggapainya. Kekuatan kebaikan yang menjadikan munculnya kerukunan, kesejahteraan sampai pada perlindungan akan kehidupan, merupakan bentuk kekuatan yang membantu manusia menuju terwujudnya harapan kesejahteraan hidup tersebut.

\section{Upacara Ruwatan Jawa dalam Wacana Pembangunan Jemaat}

Menurut Roger Weverbergh, terdapat 5 gambaran gereja, yaitu: Gereja sebagai institut keselamatan, menggunakan metafora "tubuh mistik" Kristus dengan warga gereja sebagai "masyarakat/perhimpunan sempurna"; gereja sebagai persekutuan, menunjuk pada persekutuan orang percaya, dengan metafora "tubuh Kristus”, “bangsa” maupun "perjanjian”; gereja sebagai sakramen, menggabungkan kedua aspek yang muncul dalam kehidupan bergereja, yakni aspek illahi dan aspek manusiawi; gereja sebagai saksi, mengacu pada 
konsep martir, dengan metaphor "bentara" atau "nabi"; gereja sebagai hamba, merupakan bentuk kerendahan status, yang memiliki persamaan dengan pembantu, budak. ${ }^{7}$

Selain itu terdapat 5 gambaran Allah, yaitu: sebagai yang Mahakuasa, merupakan bentuk pengenalan Allah kepada manusia melalui Abraham, Musa maupun juga para nabi lainnya; sebagai Pencipta, merupakan bentuk pengenalan umat kepada Allah, yang tidak hanya sebatas sebagai Pencipta atas segala sesuatu, tetapi juga yang memberi pembebasan dari himpitan; sebagai Tritunggal, merupakan bentuk pewahyuan Allah kepada manusia, yang dikenal manusia melalui diri pribadi Yesus Kristus, Sabda maupun Roh; sebagai Pembebas, merupakan bentuk pemahaman manusia terhadap Allah yang membongkar dan membebaskan manusia dari ketidakadilan, penindasan maupun kemiskinan; sebagai Kedalaman yang terdalam, merupakan model pewahyuan Allah kepada manusia secara langsung dalam komunikasi dan pengalaman.

Gambaran-gambaran gereja dan gambaran-gambaran Allah berkaitan atau berpasangan satu sama lain, yakni: Gambaran gereja sebagai institut keselamatan dengan gambaran Allah sebagai Yang Mahakuasa; gereja sebagai persekutuan dengan Allah sebagai Pencipta; gereja sebagai sakramen dengan Allah sebagai Tritunggal; gereja sebagai saksi dengan Allah sebagai Pembebas; gereja sebagai hamba dengan Allah sebagai Kedalaman Yang Terdalam.

Warga gereja yang menerima sekaligus mengikuti ruwatan akan "dihakimi” sebagai seseorang yang tidak menghargai keselamatan yang telah mereka terima dari Yesus Kristus. Penghakiman ini merupakan bentuk penegasan bahwa ruwatan tidak bermanfaat bagi warga gereja, bahkan sebaliknya malah sebagai pengganggu iman dan kesetiaan kepada Kristus. Dilihat dari kacamata Kristen, Jatusmati dapat disebut sebagai simbol orang-orang berdosa, yang sudah semestinya memperoleh hukuman dari Allah sendiri. Tetapi karena kasih Allah, Jatusmati juga menjadi simbol orang-orang yang menjadi sasaran keselamatan Allah, agar hidupnya terhindar dari hukuman dan laknat Allah untuk memperoleh pengampunan dan berkat-Nya. Jatusmati merupakan simbol orang yang memperoleh jalan menuju kesejahteraan dalam hidupnya, lahir maupun batin. Apapun alasannya, warga gereja tidak bisa disamakan begitu saja dengan Batara Kala, tetapi sikap "setia" Batara Kala terhadap hukum dan ketentuan yang berlaku dapat menjadi contoh bagi warga gereja.

Oleh karena tatanan yang berlaku di gereja, termasuk juga firman di Alkitab tidak menyampaikan tentang ruwatan, maka sudah semestinya ruwatan ini ditolak. Penolakan ini

\footnotetext{
${ }^{7}$ Roger Weverbergh, Gambaran-Gambaran Gereja, Seri Pastoral (Yogyakarta: Pusat Pastoral, 1998), 289.
} 
didasarkan pada pemahaman bahwa warga gereja telah memiliki "sarana" sendiri dalam menerima keselamatan rohani, kesehatan jasmani, kerukunan berkeluarga maupun berakt umur panjang. Uraian ini tidak bermaksud untuk menyejajarkan apalagi menyamakan ruwatan Jawa dengan baptisan Kristen. Tetapi keduanya diangkat sebagai contoh untuk sekedar menyampaikan bahwa keduanya merupakan sama-sama sarana atau alat yang dipakai dalam mencapai tujuan keselamatan dan kesejahteraan hidup. Melalui pengorbanan diri-Nya, Yesus Kristus sebagai sarana pendamaian Allah dengan manusia berdosa, sekaligus diri-Nya pelaku pendamaian itu. "Ewadene menawa ana kang gawe dosa, kita padha duwe pantara ana ing ngarsane Sang Rama, iya iku : Gusti Yesus Kristus kang adil. Lan Panjenengane iku kang dadi pangruwate dosa kita, lan ora ngemungake dosa kita bae, nanging malah iya dosane wong sajagad kabeh”. (I Yokanan 2 : 2). Penolakan ruwatan dikarenakan alasan ketidakinginan warga gereja akan adanya kekacauan yang muncul bersamaan dengan kehadiran atau penerimaan ruwatan. Kekuatan kejahatan telah dikalahkan oleh kekuatan Kristus, sehingga kemenangan kebaikan dan kesejahteraan atas kuasa iblis atau malapetaka adalah Yesus Kristus sendiri.

Ruwatan adalah salah satu bentuk aktivitas budaya Jawa peninggalan masa lalu, maka sebagai orang Jawa yang peduli akan "warisan leluhur" merasa perlu mengungkapkan kecintaannya dengan cara melestarikan budaya tersebut di tengah maraknya budaya populer masa kini. ${ }^{8}$ Ruwatan sebagai salah satu bagian dari sistem kemasyarakatan tidak disingkirkan, melainkan dihormati dan diakui keberadaannya. Sikap menghargai kebudayaan lokal merupakan bagian dari proses pembentukan karakter kebangsaan. ${ }^{9}$ Gereja sebaiknya juga berperan dalam pembentukan karakter bangsa melalui pelayanannya, karena gereja merupakan bagian dari masyarakat Indonesia.

Gereja dapat membuka "pintu ijin" yang mengijinkan atau memperkenankan warga gereja yang berkehendak mengikuti ruwatan. Hal ini tidak menghilangkan esensi gereja sebagai lembaga religius. Sekalipun ada lembaga adat yang berfungsi untuk memelihara kearifan lokal dan budayanya ${ }^{10}$, namun peran serta gereja untuk memelihara harta bangsa

\footnotetext{
${ }^{8}$ Daniel Syafaat Siahaan, "Pendidikan Kristiani Sebagai Instrumen Penyadaran Pentingnya Pertumbuhan Spiritualitas Dalam Konteks Budaya Populer,” Gema Teologika 1, no. 2 (2016): 123-138, http://journal-theo.ukdw.ac.id/index.php/gemateologika/article/view/218.

${ }^{9}$ Yuni Harmawati, Aim Abdulkarim, and Rahmat, "Nilai Budaya Tradisi Dieng Culture Festival Sebagai Kearifan Lokal Untuk Membangun Karakter Bangsa," Journal of Urban Society's Arts 3, no. 2 (October 31, 2016): 82-95, accessed April 1, 2018, http://journal.isi.ac.id/index.php/JOUSA/article/view/1477/328.

${ }^{10}$ Christeward Alus, "PERAN LEMBAGA ADAT DALAM PELESTARIAN KEARIFAN LOKAL SUKU SAHU DI DESA BALISOAN KECAMATAN SAHU KABUPATEN HALMAHERA BARAT," JURNAL ACTA DIURNA 3, no. 4 (November 3, 2014), accessed March 21, 2018, https://ejournal.unsrat.ac.id/index.php/actadiurna/article/view/5995/5514.
} 
tersebut dapat dipandang sebagai tugasnya di tengah dunia. Terdapat dua catatan yang perlu diperhatikan oleh gereja. Pertama, keikutsertaan warga gereja merupakan keputusan pribadinya yang telah mantap, serta melalui peristiwa ruwatan warga gereja tersebut semakin setia dalam persekutuan dengan Kristus. Kedua, permohonan yang mereka sampaikan dalam ruwatan tetap tertuju pada Yesus Kristus, Tuhan dan Juru selamatnya.

Allah sebagai Kedalaman Yang Terdalam juga mau dan mampu masuk pada kedalaman yang terdalam pada diri manusia pengguna ruwatan juga siapapaun yang ada hubungannya dengan ruwatan. Warga gereja juga menghormati makhluk lain, meski itu adalah binatang maupun juga tumbuhan dan alam. Penyelamatan dan kesejahteraan hidup yang dicari dan didapatkan oleh peserta ruwatan, bersumber pada kuasa dan tangan Allah sendiri. Warga gereja tidak perlu menggunakan mantera berjenis apapun juga, untuk maksud apapun juga. Sarana yang dipakai dalam "berkomunikasi” kepada Allah adalah doa melalui perantara Juru Selamat Yesus Kristus. Terkabulnya doa Kristen didasarkan pada iman kepada Yesus Kristus dan semuanya berada dalam kuasa Allah sendiri, bukan pihak manusia. "Sajian" yang perlu disampaikan oleh warga gereja adalah suatu ucapan syukur kepada Tuhan, setelah dirinya memperoleh keselamatan dari Allah.

\section{Relevansi antara Upacara Ruwatan dengan Gambaran Gereja dan Allah}

Ide dan makna ruwatan adalah sebagai upaya pembersihan diri sampai pada penyelamatan manusia secara jasmani dan rohani, yang dilakukan oleh Yesus Kristus. Warga gereja menyakini bahwa Yesus Kristus telah menebus manusia dari dosa-dosanya, hingga manusia dalam kondisi "bersih" dan berkenan di hadapan Allah, maka tepatlah bila digunakan istilah "Yesus Kristus Juru Ruwat Manusia"

Teologi ruwatan adalah teologi penyelamatan manusia. Ide penyelamatan berasal dari Sang Hyang Widi, yakni Allah itu sendiri. Penyelamatan yang muncul dalam peristiwa ruwatan adalah penyelamatan yang dilakukan oleh Allah Yang Mahakuasa. Baik Yesus Kristus Juru Ruwat Manusia maupun Allah sebagai Kedalaman Yang Terdalam menyampaikan ide bagaimana Allah mewahyukan dirinya kepada manusia dalam jiwa manusia. Melalui iman, penyerahan diri secara sungguh-sungguh pada "tangan" Allah inilah, keselamatan, kesejahteraan dan panjang umur dapat berlangsung. Allah tidak melakukan paksaan dalam komunikasi iman yang terdalam dengan manusia, sehingga manusia dalam berkomunikasi dan meletakkan percayanya kepada Allah sebagai Kedalaman Yang Terdalam, di dalam nama Yesus Kristus jangan sampai terjadi dalam paksaan. 
Secara sadar manusia mengakui kekurangan, kesalahan dan dosa-dosanya, berikutnya hadir di hadapan Allah memohon ampun dan bertobat kepada-Nya. Manusia diajak untuk hadir, beriman dan menyerahkan hidupnya dalam kuasa Yesus Kristus, oleh karena Ia adalah Juru Ruwat Manusia. Sejajar dengan ini, pola keselamatan dalam Kristen adalah berasal dari Allah melalui karya Yesus Kristus di dalam wafat dan kebangkitan-Nya. Ruwatan merupakan suatu peristiwa di tengah masyarakat Jawa, yang difungsikan untuk membebaskan manusia dari kesengsraan, malapetaka dan rintangan yang menghadang manusia dalam perjalanan hidupnya. Siraman dipahami sebagai simbol pembersihan seseorang dari sukerta yang melekat pada dirinya.

Ada pandangan terhadap realitas ruwatan yang berlangsung di tengah masyarakat Gereja Kristen Jawa, seperti beberapa hal berikut:

Pertama, pandangan yang menolak ruwatan; didasarkan pada alasan bahwa warga gereja telah menerima keselamatan dari Yesus Kristus. Untuk itu kehidupannya diserahkan kepada kuasa Yesus Kristus saja, sehingga kuasa dan apapun juga di luar Kristus ditolaknya.

Kedua, pandangan menyetujui ruwatan; didasarkan pada alasan ikut melestarikan budaya Jawa. Orang-orang dalam kelompok ini tetap meletakkan percayanya, keselamatannya kepada Yesus Kristus. Sedangkan ruwatan disetujuinya, oleh karena dalam ruwatan terdapat hal-hal positif dan baik, misalnya upaya untuk memperoleh kesejahteraan hidup. Gereja di tengah masyarakat harus dapat memberikan perannya, termasuk dalam menjaga budaya yang menjadi identitas kebangsaan. ${ }^{11}$ Tentunya, hal tersebut tidaklah bertentangan dengan iman Kristen.

Ketiga, pandangan yang netral; didasarkan pada alasan "demokrasi” berpendapat dan bertindak perlu dikembangkan dalam gereja, sehingga masing-masing warga menghormati pandangan orang lain, meski berbeda dengannya. Selain itu didasarkan pada alasan agar persoalan tersebut menunggu hasil keputusan yang dikeluarkan oleh pihak gereja.

\section{Kesimpulan}

Upacara ruwatan sesungguhnya menyampaikan simbol-simbol atau lambang-lambang yang terungkap lewat peran-peran yang ditampilkan oleh tokoh-tokoh dan hal-hal yang terkait dengan upacara ruwatan. Batara Kala sebagai simbol kejahatan. Ki Dalang Kandabuwana sebagai simbol penyelamatan kehidupan. Jatusmati adalah simbol sukerta dan terkena malapetaka. Perbuatan Batara Guru sebagai simbol munculnya si Jahat dan malapetaka.

\footnotetext{
${ }^{11}$ Jermia Djadi, "PERANAN PEMUDA GEREIA DALAM PEMBANGUNAN BANGSA,” Jurnal Jaffray 3, no. 1 (2005): 41-46.
} 
Mantera sebagai simbol kekuatan gaib Ki Dalang Kandabuwana. Sajian sebagai simbol kelengkapan ruwatan. Isi besar dari teks ruwatan murwakala adalah suatu usaha di dalam manusia mencari kesejahteraan hidup. ${ }^{12}$ Sebesar apapun juga kekuatan si jahat pada akhirnya dapat ditundukkan oleh kekuatan sang benar, selain itu masih terdapat nilai "mengejutkan" yakni adanya pertobatan untuk menjadi orang atau sosok yang baik.

Dalam konteks ruwatan, istilah Yesus Kristus Juru Ruwat Manusia mengandung arti, bahwa Yesus Kristus adalah sosok yang menolong manusia dari kematian jasmaniah, memberi kerukunan dan kesejahteraan hidup bersama, membebaskan manusia dari malapetaka dan penderitaan hidup, mampu mengalahkan kuasa kegelapan dan kejahatan, memberi berkat dan kebutuhan hidup serta membersihkan manusia dari kesalahannya. Gereja sebagai hamba bersikap mau mengakui, menerima dan menghormati keberadaan ruwatan Jawa; ikut menjaga keberadaan ruwatan sebagai bagian dari aktivitas masyarakat Jawa sesungguhnya termasuk pelayanan gereja.

\section{Rekomendasi}

Beberapa hal yang dapat menjadi rekomendasi adalah:

Pertama, warga gereja secara pribadi maupun gereja sebagai lembaga tidak perlu menunjukkan sikap antipati terhadap ruwatan.

Kedua, majelis gereja tidak perlu menjatuhkan pamerdi (siasat gerejawi) terhadap warga gereja peserta ruwatan Jawa.

Ketiga, ruwatan dapat digunakan sebagai wadah atau bungkus, yang mana gereja dapat memberikan isi yang sesuai dengan Injil Yesus Kristus.

Keempat, istilah Yesus Kristus Juru Ruwat manusia merupakan istilah yang ngristeni (bersifat Kristen) dan njawani (bersifat Jawa) yang bagi masyarakat berlatarbelakang budaya Jawa akan lebih nges (mantap) di iman dan rasa (perasaan intuitif).

Kelima, penelitian tentang ruwatan Jawa ini memiliki keterbatasan, di mana belum mencakup seluruh pengertian dan makna ruwatan; masih banyak sisi-sisi ruwatan Jawa yang dapat diteliti dan diamati, misalnya dari sejarahnya ataupun pelaksanaannya. Demikian pula budaya Jawa pada umumnya dapat diteliti dalam rangka pembangunan jemaat yang didasarkan pada budaya Jawa.

\footnotetext{
${ }^{12}$ Sugeng Rahanto, "PENGARUH RUWATAN MURWOKOLO TERHADAP KESEHATAN."
} 


\section{Referensi}

Alus, Christeward. "PERAN LEMBAGA ADAT DALAM PELESTARIAN KEARIFAN LOKAL SUKU SAHU DI DESA BALISOAN KECAMATAN SAHU KABUPATEN HALMAHERA BARAT." JURNAL ACTA DIURNA 3, no. 4 (November 3, 2014). Accessed April 11, 2018. https://ejournal.unsrat.ac.id/index.php/actadiurna/article/view/5995/5514.

Anugrah, Diana. "ANALISIS SEMIOTIKA TERHADAP PROSESI PERNIKAHAN ADAT JAWA \&quot;TEMU MANTEN\&quot; DI SAMARINDA" 4, no. 1 (2016): 319-330. Accessed March 21, 2018. http://ejournal.ilkom.fisip-unmul.ac.id/site/wpcontent/uploads/2016/04/JURNAL GANJIL diana (04-23-16-04-46-50).pdf.

Djadi, Jermia. "PERANAN PEMUDA GEREIA DALAM PEMBANGUNAN BANGSA." Jurnal Jaffray 3, no. 1 (2005): 41-46.

Harini, Ninik. "MAKNA SIMBOLIS SRIMPI LIMA PADA UPACARA RUWATAN DI DESA NGADIRESO PONCOKUSUMO MALANG." Bahasa dan Seni : Jurnal Bahasa, Sastra, Seni, dan Pengajarannya 40, no. 1 (2012). Accessed April 1, 2018. http://journal2.um.ac.id/index.php/jbs/article/view/122/95.

Siahaan, Daniel Syafaat. "Pendidikan Kristiani Sebagai Instrumen Penyadaran Pentingnya Pertumbuhan Spiritualitas Dalam Konteks Budaya Populer.” Gema Teologika 1, no. 2 (2016): 123-138. http://journaltheo.ukdw.ac.id/index.php/gemateologika/article/view/218.

Sugeng Rahanto. "PENGARUH RUWATAN MURWOKOLO TERHADAP KESEHATAN.” Buletin Penelitian Sistem Kesehatan. 15, no. 3 (2012): 282-288. Accessed March 26, 2018. http://ejournal.litbang.depkes.go.id/index.php/hsr/article/view/3002/2236.

Sunarno. "Indigenous : Jurnal Ilmiah Berkala Psikologi." Indigenous: Jurnal Ilmiah Psikologi 11, no. 2 (November 1, 2009). Accessed April 6, 2018. http://journals.ums.ac.id/index.php/indigenous/article/view/1619/1152.

Weverbergh, Roger. Gambaran-Gambaran Gereja, Seri Pastoral. Yogyakarta: Pusat Pastoral, 1998.

Yuni Harmawati, Aim Abdulkarim, and Rahmat. "Nilai Budaya Tradisi Dieng Culture Festival Sebagai Kearifan Lokal Untuk Membangun Karakter Bangsa." Journal of Urban Society's Arts 3, no. 2 (October 31, 2016): 82-95. Accessed April 1, 2018. http://journal.isi.ac.id/index.php/JOUSA/article/view/1477/328.

Zoest, Aart van, "Interpretasi dan Semiotika" dalam Panuti Sudjiman dan Aart van Zoest (Penyunting), Serba-Serbi Semiotika, Jakarta, Gramedia Pustaka Utama, 1992. 